\title{
INCLUSÃO ESCOLAR DE CRIANÇAS COM SÍNDROME DE DOWN: EXPERIÊNCIAS CONTADAS PELAS FAMÍLIAS ${ }^{1}$ \\ SCHOOL INCLUSION OF CHILDREN WITH DOWN SYNDROME: EXPERIENCES TOLD
}

\author{
BY FAMILIES
}

\author{
Flávia Mendonça Rosa LUIZ² \\ Lucila Castanheira NASCIMENTO
}

\begin{abstract}
RESUMO: este trabalho teve como objetivo explorar as experiências de famílias no processo de inclusão de crianças com síndrome de Down na rede regular de ensino. O objetivo foi conhecer as potencialidades e limitações vividas por essa clientela, no período de transição da instituição especializada para a escola regular e, assim, levantar as necessidades de cuidado, com vistas à promoção de saúde dessas famílias. Trata-se de um estudo de casos múltiplos, de abordagem qualitativa. Participaram da pesquisa 11 mães e um pai de crianças com Síndrome de Down, cujas crianças frequentaram uma instituição especializada e foram encaminhadas para a rede regular de ensino de um município do interior paulista. Os resultados evidenciaram a necessidade de acompanhamento das famílias, antes, durante e após a inclusão propriamente dita, de modo a apoiá-las nos momentos de busca e escolha da escola, de adaptação da criança ao novo ambiente e de transição dos atendimentos oferecidos pela instituição especializada para outros setores. O conhecimento produzido neste estudo tem a intenção de tornar o processo de inclusão da criança com Síndrome de Down, na rede regular de ensino, uma etapa a ser vivida por ela e sua família da melhor forma possível, sentindo-se preparadas e acolhidas.
\end{abstract}

PALAVRAS-CHAVE: Educação Especial. Síndrome de Down. Família. Inclusão.

\begin{abstract}
This study aimed to explore families' experiences in the inclusion process of children with Down syndrome into mainstream education, so as to get to know the potentials and limitations these clients experience during the transition period from the specialized institution into regular education and, thus, survey care needs with a view to these families' health promotion. A multiple case study with a qualitative approach was carried out. Study participants were 11 mothers and one father of children with Down syndrome, whose children attended a specialized institution and were referred to the mainstream education network in an interior city in state of São Paulo. The results showed the need to monitor the families before, during and after the inclusion itself, so as to support them when searching and choosing the school, adapting the child to the new environment and during the transition between care offered at the specialized institution and other sectors. The goal of the knowledge produced in this study is to make the inclusion process of children with Down syndrome into mainstream education a phase the children and their families experience as positively as possible, feeling prepared and welcomed.
\end{abstract}

KEYWORDS: Special Education. Down Syndrome. Family. Inclusion.

\footnotetext{
${ }^{1}$ Manuscrito derivado de dissertação de mestrado, defendida na EERP/USP.

${ }^{2}$ Fonoaudióloga, Mestre em Enfermagem em Saúde Pública pela Escola de Enfermagem de Ribeirão Preto da Universidade de São Paulo. Doutoranda do Programa de Pós-Graduação em Enfermagem em Saúde Pública da EERP/USP. flaviamrosa@hotmail.com

3 Enfermeira. Professora Associada do Departamento de Enfermagem Materno-Infantil e de Saúde Pública da EERP/USP, Centro Colaborador da Organização Mundial de Saúde (OMS) para o Desenvolvimento da Pesquisa em Enfermagem, Capítulo Rho Upsilon, Sigma Theta Tau International, Honor Society of Nursing.: lucila@eerp. usp.br
} 


\section{INTRODUÇÃo}

A inclusão escolar é uma prática cada vez mais frequente em vários países, e a maneira como ela acontece está intimamente relacionada à cultura local e à sua política (LUIZ et al., 2008). Em países como o Egito, por exemplo, o Ministério da Educação está empenhado em fornecer às crianças com necessidades especiais uma educação que permita a elas viver em sociedade (ABDELHAMEED, 2010). Da mesma forma, na Nova Zelândia, receber o estudante com síndrome de Down em uma escola regular é prática aceitável há mais de dez anos (HOLDEN; STEWART, 2002). Por outro lado, na Holanda, a falta de oportunidade para introduzir a criança em uma escola regular ocorre porque a área geográfica em que a família reside não oferece escola (CUCKLE, 1999), ou ainda porque as escolas primárias não são obrigadas a aceitar crianças com atraso no desenvolvimento, o que torna a inclusão seletiva (DE GRAAF, 2002). Em Lisboa, Portugal, dados de uma pesquisa mostraram que as escolas inclusivas, mesmo contendo em seu quadro a presença de professores de ensino especial, ainda não possuem, em termos físicos e materiais, condições ideais e carecem de uma visão de educação e de inclusão mais ampla (DORZIAT, 2009).

No Brasil, a educação inclusiva fundamenta-se na Constituição Federal de 1988 (BRASIL, CONSTITUIÇÃO, 1988), a qual garante a todos o direito à igualdade $\left(\operatorname{art.~} 5^{\circ}\right)$. No seu artigo 205, trata do direito de todos à educação, visando ao pleno desenvolvimento da pessoa, a seu preparo para o exercício da cidadania e a sua qualificação para o trabalho (BRASIL, MINISTÉRIO PÚBLICO FEDERAL, 2004). Em conformidade com tal Constituição, o Congresso Nacional, por meio do Decreto Legislativo $\mathrm{n}^{\circ}$ 198, de 13 de junho de 2001, aprovou nova lei baseada no disposto da Convenção de Guatemala que trata da eliminação de todas as formas de discriminação contra a pessoa portadora de deficiência e deixa clara a impossibilidade de tratamento desigual aos deficientes (BRASIL, MINISTÉRIO PÚBLICO FEDERAL, 2004). Paralelamente a esses documentos, declarações internacionais, como a Declaração Mundial sobre Educação para Todos (UNESCO, 1990), e a Declaração de Salamanca (SALAMANCA, 1994), reforçam movimentos em favor de uma educação inclusiva, afirmando uma situação de igualdade de direitos entre os cidadãos (OLIVEIRA, 2004).

Particularmente, em um município do interior paulista, a inclusão é favorecida pela parceria entre a Secretaria da Educação e a Associação de Pais e Amigos dos Excepcionais (APAE), instituição que é fruto do trabalho de um grupo de pais preocupados com a escolaridade e atendimento de seus filhos portadores de deficiência. A APAE desse município desenvolve vários programas, dentre eles a Educação Precoce ou Setor de Estimulação Precoce que atende crianças de zero a quatro anos que apresentam atraso no desenvolvimento neuropsicomotor e deficiência instalada e conta com o trabalho de uma equipe multidisciplinar composta por fisioterapeutas, terapeuta ocupacional, fonoaudiólogas, psicóloga e pedagogas. Ao chegarem à instituição, as famílias são recebidas por essa equipe que oferece atendimentos às crianças, além de orientações, no que diz respeito ao trabalho que deve ser realizado em casa com as mesmas. 
Em sua maioria, as crianças que frequentam a Estimulação Precoce são portadoras da síndrome de Down (SD), e dentre os objetivos deste programa está a preparação destas crianças, pela equipe, para posterior encaminhamento à inclusão na rede regular de ensino, já que, desde 2003, com a parceria entre a APAE e a prefeitura, as crianças que frequentam a instituição, especificamente aquelas do setor de Estimulação Precoce, são encaminhadas para a escola regular. Com base nesse panorama, desenvolvemos um estudo cujo objetivo foi o de explorar as experiências dessas famílias no processo de inclusão da criança com SD, na rede regular de ensino, já que pouco se sabe sobre como tem sido a transição das mesmas para a escola regular e, especificamente, como se caracterizam as experiências das crianças e suas famílias que passam por este processo. Os resultados evidenciaram a experiência da família desde o processo de diagnóstico da criança com SD, com suas consequências na dinâmica familiar; o preparo para a inclusão; a inclusão propriamente dita e a reflexão da família sobre a sua experiência. Neste artigo, propomo-nos a apresentar parte dessa experiência, particularmente aquela relacionada ao processo de transição para a primeira inclusão, a fim de subsidiar os profissionais no planejamento do cuidado das famílias de crianças com SD que vivem o processo de inclusão, com vistas à sua promoção de sua saúde.

\section{MÉTOdo}

Para atingir os objetivos desta pesquisa, optamos pela condução de um estudo de casos múltiplos, de natureza qualitativa. $\mathrm{O}$ protocolo de pesquisa foi submetido à revisão ética e ao acompanhamento de um Comitê de Ética em Pesquisa, tendo sido aprovado.

Participaram deste estudo 11 mães e um pai de crianças com SD, totalizando 12 participantes e 11 famílias. Estabeleceram-se como critérios de inclusão as famílias que possuíssem crianças com síndrome de Down, que foram acompanhadas pelo setor de Estimulação Precoce da Associação de Pais e Amigos dos Excepcionais (APAE) da cidade onde a pesquisa foi conduzida, e que também foram encaminhadas para a rede regular de ensino em 2003, 2004 e 2006, anos em que se deu a prática de inclusão na APAE. Dentre as famílias potenciais para o estudo, optamos por aquelas residentes no próprio município onde o estudo foi conduzido, em virtude de limitação de recursos e de tempo para coleta de dados. Elegeu-se para a entrevista o principal cuidador da criança, por acreditar que ele pudesse informar com mais detalhes a experiência do processo de inclusão. Naquelas famílias em que mais de um cuidador demonstrou interesse em ingressar no estudo, incentivou-se tal participação. Assim, em uma família, o pai e a mãe da criança participaram da pesquisa.

Os dados foram coletados de março a julho de 2008, por meio de entrevistas semiestruturadas que foram realizadas, em sua maioria, em um único encontro, no domicílio das crianças ou no local de trabalho de algumas mães, conforme disponibilidade, viabilidade e escolha dos participantes. Para tanto, 
elaborou-se o Termo de Consentimento Livre e Esclarecido que era entregue ao participante, anteriormente ao início da entrevista. Para preservar o anonimato dos participantes, seus nomes verdadeiros foram substituídos pelas iniciais " $\mathrm{M}^{\text {", }}$ no caso de ser a mãe e " $\mathrm{P}$ ", para o pai. Aliada à letra $\mathrm{M}$ ou $\mathrm{P}$, acrescentaram-se os números arábicos de 1 a 11, de acordo com a entrada da família no estudo.

As análises das entrevistas ocorreram em etapas, segundo orientações de Mayan (2001) para análise de conteúdo. O primeiro passo foi a codificação que consistiu na familiarização dos dados e no início da organização da informação. Após a codificação, foi feita a categorização dos dados, na qual os autores fizeram a releitura dos mesmos, recortaram as seções subtraídas do texto e as separaram em categorias ou subcategorias, incluindo os dados de maneira significativa e manejável. Para finalizar, integraram-se as categorias, relacionando-as e descobrindo um tema comum entre os dados (MAYAN, 2001).

\section{Resultados E Discuss Ão}

Neste relato de pesquisa, como já exposto, apresentamos parte dos resultados de um estudo que explorou as experiências das famílias de crianças com SD no processo de inclusão, na rede regular de ensino. Tais resultados compreendem a categoria denominada:

\subsection{O PROCESSO DE TRANSIÇÃO PARA A PRIMEIRA INCLUSÃO}

As crianças, cujas famílias participaram deste estudo, entraram na APAE logo após o nascimento, com idade variando entre dois e sete meses, e foram encaminhadas para a rede regular de ensino, preferencialmente para as Escolas Municipais de Educação Infantil (EMEIs) ou creches municipais, quando tinham entre dois e quatro anos. Com a iminência da inclusão, as mães das crianças que seriam inseridas, na escola regular, passaram a receber, seis meses antes de serem encaminhadas, atendimentos em grupo com a psicóloga, onde foram abordados e esclarecidos aspectos sobre a inclusão. Foi na APAE que as famílias se sentiram acolhidas e supridas no que diz respeito aos atendimentos e ao apoio emocional e, por esse motivo, a maioria delas não se sentia preparada quando foram encaminhadas para a inclusão, mesmo após o trabalho que a instituição fez com as mães, em relação a esse processo.

Além da dúvida em relação ao momento certo para se iniciar o processo de inclusão da criança na rede regular de ensino, outras questões permearam esse período, dentre elas, a preocupação em relação à continuidade dos atendimentos clínicos especializados da criança com SD na instituição especializada, a busca $e$ seleção da escola regular e a necessidade ou não de um conhecimento prévio da escola. 


\subsubsection{SERÁ QUE É A HORA CERTA?}

Como já relatado, a partir de 2003, por meio da parceria entre a APAE e a prefeitura da mesma cidade, as crianças que frequentavam o setor de Estimulação Precoce desta instituição, e após avaliação da equipe responsável, deveriam ser encaminhadas para a rede regular de ensino. Dessa forma, todas as famílias receberam encaminhamento para a escola regular por meio da $\mathrm{APAE}$, com exceção de uma mãe que, por opção, inseriu seu filho na escola antes de ser encaminhado.

Durante os encontros, as mães verbalizaram, com clareza, os motivos que levaram as crianças a serem encaminhadas da instituição especializada para a escola regular. Uma das participantes da pesquisa nos explicou que sua filha foi encaminhada "por causa da idade e por causa que ela já tava bem preparada pra entrar pra escola mesmo (M4)"; outra nos esclareceu que os profissionais da APAE disseram a ela "que era bom pôr ele [criança com SD] na inclusão" (M11). Outros depoimentos ilustram as razões de amadurecimento e idade das crianças como motivadores do encaminhamento das crianças:

Eles [referindo-se aos profissionais da APAE] deram alta pra ele. [...] Na época, ele [profissional da APAE] chegou pra mim e disse que não tinha necessidade do [criança com SD] ficar lá, que ele já tinha desenvolvido a meta que ele tinha que ter desenvolvido (M5)

Lá na APAE, eles me informaram que ele [criança com SD] ficava até 3 anos, 3 anos e meio. Era o máximo que ele ia ficar lá. Depois ele ia ter que enfrentar uma escola, ou seja, uma creche, qualquer outra escola. (M3)

As mães, em sua maioria, apesar de estarem sendo preparadas para a inclusão, em um período prévio de seis meses à sua efetivação, não ficaram satisfeitas quando seus filhos foram encaminhados para a escola regular. Segundo elas, as crianças ainda estavam muito novas para a inclusão e deveriam permanecer mais tempo na APAE, por haver ainda muito a aprender:

A gente [pai e mãe] teve muito medo mesmo. Porque ele [criança com SD] era um bebê [quando foi para a inclusão]. Se fosse ver ele era um bebê. Quase não falava ainda. Ainda fazia xixi, cocô na fralda. (M3)

No meu ponto de vista a APAE tinha que jogar a criança cá fora pelo menos uns $30 \%$ alfabetizado, porque aí era mais fácil para os profissionais aqui fora receber. (M4)

O progresso no desenvolvimento da criança também foi um dos aspectos que contribuiu para reforçar, na perspectiva da Mãe 6, a saída precoce da mesma da APAE. Para ela, "tava sendo tão bom [o desenvolvimento da criança com SD, na $\mathrm{APAE}$ ] que a gente [pai e mãe] queria que ele ficasse mais um ano na APAE" (M6).

Algumas mães se mostraram resistentes para procurar a escola regular, mesmo depois de terem tido tempo e espaço para o amadurecimento dessa nova ideia, por meio da realização de um grupo de mães, coordenado por profissional 
da instituição especializada. O principal motivo das mães para postergar tal busca foi o sentimento de conforto trazido pela APAE, já que lá os profissionais sabiam como lidar com seus filhos, transmitiam segurança, conforto e experiência com as particularidades das crianças, como demonstra a fala a seguir:

No começo quando a gente teve a notícia que eles [crianças com SD] não iriam mais ficar na APAE e viria pra escola, eu tive dúvidas. Não sei se é bem medo, mas é uma insegurança, porque lá na APAE você acaba depositando uma confiança porque são profissionais preparados. Além de serem preparados, estão acostumados a lidar com todo tipo de deficiência. Tem uma experiência muito grande, é uma sala menor com poucas crianças. (M1)

Além disso, como relatou a Mãe 9, havia o medo, com a saída da APAE, de que a filha deixasse de receber os atendimentos clínicos oferecidos pela instituição e, além disso, viesse a perder o vínculo com os profissionais de lá:

Aí foram feitas várias reuniões com a psicóloga e com a diretora sobre a inclusão, e aí a gente [mãe e pai], como se diz, encarou, né?, com medo, porque a gente já tinha pego confiança nos profissionais da APAE. Medo de que nas escolas ela não ia ter a mesma coisa que ela tinha na APAE, dos profissionais. [...] No começo, a gente ficou meio inseguro, até a gente falou assim: "Não é hora deles [crianças com $\mathrm{SD}$ ] ficarem mais um pouco?" Agora que eles [crianças com SD] começaram ... [interrompeu a sua fala]. (M9)

A preocupação da Mãe 9, com a descontinuidade da atenção à criança e rompimento do vínculo, revela a necessidade de uma interlocução entre os serviços de saúde e o educacional, como é reforçado por Gonçalves et al. (2008), no sentido de dar o seguimento ao trabalho realizado na instituição especializada, bem como na intenção de facilitar a comunicação entre família, escola, e instituição especializada, para que se estabeleça uma relação de confiança entre elas. Tal estratégia apresenta potencial para estreitar laços, de modo a facilitar o processo de transição da criança para a rede regular de ensino. O rompimento brusco do vínculo entre criança, família e equipe responsável pelo seguimento da criança com SD até a chegada da inclusão na rede regular pode ser desencadeador de situações estressantes para a família, sentimentos de desamparo e desestímulo para o enfrentamento desse novo período. Certamente, esse processo deve ser iniciado com tempo hábil, para que todos os envolvidos tenham condições de se adaptar e, ainda, para que as dificuldades enfrentadas no processo possam ser revisitadas e amenizadas da melhor forma possível.

Outros medos foram expressos de diversas formas pelas mães, no momento em que elas foram encaminhadas para a rede regular de ensino. $\mathrm{Na}$ maioria das vezes, esses medos estavam relacionados à indiferença, ao preconceito e à consequente rejeição, tanto das crianças quanto de pais e professores. Uma das mães verbalizou que seu medo era "de não tratar bem ele [criança com SD], deixar ele largado, deixar ele num canto, por exemplo, dar um brinquedo pra 
ele" (M2). Essa mesma mãe finalizou sua fala, dizendo: “Ah! Ele é Down!” (M2), demonstrando sua preocupação em relação à possibilidade de rejeição de seu filho, por conta de sua condição.

Outros trechos ilustram as dimensões desses medos, os quais, ao longo da inclusão, foram dando lugar a sentimentos de tranquilidade:

Eu ficava muito com medo de preconceito, dele [criança com SD] ser rejeitado. Mas aí depois quando eu passei a ver que não ia acontecer isso, eu já fiquei mais sossegada. Ele não teve rejeição de nenhuma das crianças da escola, as crianças davam muita atenção pra ele. (M5)

Eu tinha medo assim, das crianças [da escola regular] judiar [da criança com SD] e do próprio profissional, o professor excluir. (M4)

A rejeição é um aspecto presente, da mesma forma, no estudo de Leal (2006), no qual algumas mães participantes temiam o preconceito por parte de professores e de pais. No nosso contexto, não é difícil compreendermos a origem do medo em relação ao preconceito e à rejeição, pois se observa a tendência de estigmatizar a pessoa com deficiência e reconhecê-la pelo rótulo. Por ser uma síndrome com características fenotípicas marcantes, é comum que pessoas com essa alteração genética causem estranheza e sejam rotuladas. Além do mais, existe o fato de, frequentemente, observarmos a inabilidade de indivíduos para lidar com elas, já que a previsibilidade é uma característica das relações sociais (SILVA, 2006).

\subsubsection{Preparando para a inclusão: a manutenção do desenVolvimento da criança COMO FOCO DE PREOCUPAÇÃO}

A continuidade do acompanhamento clínico especializado da criança foi aspecto revelado pelos participantes como de grande importância, ao se pensar na inclusão da criança com SD na rede regular de ensino. A maioria dos participantes da pesquisa, preocupados em dar seguimento ao atendimento clínico de seus filhos, quando estes saíssem da APAE, buscou a continuidade do tratamento especializado, com destaque à área de fonoaudiologia, antes mesmo de a criança deixar de ser acompanhada pela instituição especializada. Essa preocupação fundamentava-se no receio da possibilidade de uma estagnação no processo de desenvolvimento da criança, principalmente daquele relacionado às aquisições de linguagem. Tal preocupação se confirma no relato da Mãe 1, ao referir ter de "correr atrás do prejuízo" (M1), após a saída da criança da APAE. Segundo Takase e Chun (2010), a fonoaudiologia é de grande importância, já que, quanto mais efetiva a comunicação do aluno com necessidades especiais no contexto escolar, maiores são suas chances de inserção.

Cada família se mobilizou de maneira diferente, de acordo com suas possibilidades, capacidade de buscar informação e articulação com outras pessoas que passavam pela mesma experiência. A maioria delas optou por oferecer à 
criança atendimento especializado particular e, outras famílias, por condições financeiras limitadas, buscaram, por iniciativa própria, os serviços oferecidos na rede pública. Dentre os participantes do estudo, apenas uma mãe nos revelou a interrupção completa do tratamento especializado do filho, iniciado no âmbito da APAE, sem, contudo, nos expor o motivo.

Exemplificando o exposto, descrevemos o fato relatado pela Mãe 4, por ocasião da saída da criança da APAE. Em virtude do desconhecimento do atendimento especializado oferecido no setor público e, ainda, por refletir que esse serviço prestado pelo setor privado seria demasiadamente custoso para a condição financeira da família, deixou a criança durante seis meses sem esse tratamento, até vir a ser informada sobre a possibilidade do oferecimento desse serviço, sem custos, por meio de um Centro de Atividades Educacionais Especializadas. A esse respeito, ela nos disse:

Quando eu saí da APAE, eu fiquei seis meses sem atendimento pra ela [referindose à criança com SD]. Aí, eu corri atrás. Eu ficava pensando: “Ai meu Deus, eu não dou conta de pagar uma fono!" Pensava que era aquela coisa grande e não era. Aí, uma colega minha me informou lá do Centro Especializado. Fui, fiquei lá, acho, que uns três anos. [referindo-se ao tempo em que a criança com SD recebeu atendimento naquele serviço, pois depois, a família optou pelo atendimento especializado particular para a criança] (M4)

Como observado no depoimento anterior, a busca da Mãe 4 pela continuidade do tratamento da criança se deu de maneira solitária e sem informações que pudessem ajudá-la nessa busca. Tal fato nos mostra a importância de se estabelecer uma comunicação entre profissionais da instituição especializada, escolas e órgãos públicos, a fim de informar as famílias a respeito das possibilidades de dar seguimento aos atendimentos dos filhos, quando esses se desvinculam da APAE, já que para eles é de fundamental importância a não interrupção desse tratamento.

\subsubsection{A BUSCA E A SELEÇÃO DA ESCOLA}

De acordo com orientação dada pela APAE e Secretaria da Educação do município onde foi desenvolvida a pesquisa, as mães deveriam procurar uma escola municipal, próxima de suas residências, para inserir seus filhos. Apenas uma das famílias incluídas na pesquisa recebeu indicação nominal da escola para inclusão da criança. Diante desta orientação, as famílias foram em busca das escolas, tendo como referência o bairro, como haviam sido informadas, mas também levando em conta a indicação de algum parente ou a escola onde algum irmão já estava ou esteve matriculado. Apenas três famílias, das onze entrevistadas, optaram pela escola particular. Dentre essas três, duas delas acharam que seus filhos eram ainda muito jovens para frequentar a EMEI e que havia uma quantidade excessiva de alunos dentro da sala de aula nas escolas públicas. Além disso, a escola particular, 
na perspectiva dessas três mães, traz a elas a possibilidade de seus filhos serem mais bem cuidados:

Aí eu tentei matricular ele [criança com SD] aqui perto [da residência] numa EMEI, só que aí era muita criança. [...] Tava com bastante aluno na sala. E aqui também [na EMEI] ele já ia fazer o pré1 e eu tava achando ele muito imaturo pra fazer o pré 1 . E lá [na escola particular] eu tive a oportunidade de pôr ele no maternal ainda. [...] a escola particular eu acho que ela tem mais responsabilidade com o aluno. (M3)

Quando ele [criança com SD] saiu de lá [da APAE], o coordenador [da estimulação precoce da APAE] falou pra mim que era essencial eu colocar ele numa EMEI. Era o EMEI que era responsável para pegar as crianças que estavam saindo de lá. Mas como eu fiquei com um pouco de medo de colocar ele numa escola assim, aí eu fui e procurei uma escola particular que eu achava que era mais certo, que ele ia ter mais cuidados. Eu fiquei com um pouco de receio, porque ele era muito novinho ainda, então eu fiquei com um pouco de receio de procurar um EMEI pra ele. (M5)

\subsubsection{CONHECER A ESCOLA}

A necessidade de conhecer ou não a escola, previamente à inserção das crianças, não se deu da mesma forma para todas as famílias. Algumas mães conheceram onde seus filhos iriam estudar, anteriormente à entrada deles na escola. Outras, apenas no dia em que iniciaram as aulas, e algumas famílias não acharam necessário um conhecimento prévio, por já terem outros filhos na mesma escola e já estarem familiarizados com a sua dinâmica:

Assim que eles [a APAE] falaram da creche, ele [pai] foi [conhecer a creche]. Muito antes dele [criança com SD] sair [da APAE]. (M6)

Mas eu já conhecia [a escola regular onde o filho iria estudar]. A minha outra filha estudou lá há muito tempo atrás. (M7)

Eu nunca tinha passado nem na porta da escola a qual ele [criança com SD] ia tá sendo matriculado. Eu fui lá no susto pra fazer essa matrícula pra ele. Aí que eu fui conhecer a escola, depois quando começou. (M1)

Conhecer a escola anteriormente à efetivação do processo de inclusão não significa que a família terá a oportunidade, também, de conhecer a professora da criança nesse momento, já que as decisões tomadas na escola acerca das turmas de cada professor não são costumeiramente disponibilizadas para as famílias com antecedência. Entretanto, vale a pena ressaltar que visitar a instituição escolar previamente à inserção da criança certamente tem o seu valor, na medida em que tal ação tem potencial para diminuir a ansiedade da família. Contudo, mesmo conhecendo a escola com antecedência, ainda pode permanecer uma situação de tensão familiar, já que as características do professor e sua experiência prévia, da mesma forma, estão diretamente ligadas ao sucesso da inclusão.

Neste estudo, algumas mães nos relataram que, apesar de terem tido a oportunidade de visitar a escola onde o filho seria incluído, só vieram a conhecer a professora de classe no primeiro dia de inclusão da criança: 
A gente [pai e mãe] conheceu tudo [a escola onde o filho iria estudar], no dia que começou as aulas. (M11)

Antes de começar [as aulas na escola regular], eles me mostraram as professoras [professoras de modo geral, sem especificar qual seria a do seu filho]. Aí no dia que ele [criança com SD] começou [a aula], eu conheci a professora dele. (M10)

A Mãe 9 por ter participado de uma reunião na escola, anteriormente à entrada da criança na mesma, pôde conhecer e trocar informações com a professora, antes de iniciarem as aulas, estreitando vínculos. Esse fato favoreceu a troca de apoio e o fortalecimento da confiança mútua entre elas:

Antes de começar as aulas teve uma reunião, foi onde eu conheci a professora. Uma excelente profissional. Me passou muita segurança. Antes da [criança com $\mathrm{SD}$ ] ela pegou uma criança que tinha convulsão. Aí ela me disse que isso foi uma experiência pra ela, e com a [criança com SD] ia ser outro tipo de experiência, e que ela precisava do meu apoio e eu do dela também. Quer dizer, ela botou confiança em mim e eu coloquei nela. Foi onde eu me senti segura nisso. E graças a Deus ela foi, desenvolveu na creche muito bem. (M9)

Conhecer a escola e o profissional que irá trabalhar com o filho, antes de sua entrada na instituição de ensino, pode ajudar a amenizar os medos e inseguranças que as mães sentem durante o processo de transição. Além disso, é um bom momento para estabelecer o vínculo entre escola e família e fornecer ao professor informações das inabilidades e potencialidades da criança que está sendo inserida. De acordo com Ferraz; Araújo; Carreiro, (2010), a escola deve propiciar condições de comunicação entre pais e professores, para que estes compartilhem conhecimentos indispensáveis para a inclusão. Contudo, pela falta de acompanhamento dos profissionais da APAE e Secretaria da Educação municipal, revelada, pelos participantes, poucas mães tiveram essa oportunidade. Quando esse apoio ocorreu, neste estudo, ele foi disponibilizado por profissional contratado pela própria família, como, por exemplo, pela Família 3. Nesse caso, a Mãe 3 nos revelou que, no processo de conhecer a escola, ela teve a oportunidade de ser acompanhada pela terapeuta ocupacional da criança, o que a confortou.

Apesar de reconhecermos a importância da articulação entre os profissionais da APAE, da escola e da família, principalmente durante o período de transição da criança com SD para a sua primeira entrada na rede regular de ensino, isso nem sempre ocorreu. Ao longo das conversas com os participantes deste estudo, eles nos revelaram a falta de apoio para enfrentar esse período. Especificamente, mencionaram a ausência de articulação entre os profissionais, tanto da esfera da educação quanto da saúde.

A falta de integração dos diferentes setores e a fragmentação do trabalho não é aquilo que preconiza a Política Nacional de Humanização que defende a continuidade da assistência, a articulação entre os serviços e a valorização dos diferentes sujeitos implicados no processo de produção de saúde (BRASIL, 
MINISTÉRIO DA SAÚDE, 2004). A esse respeito, entendemos que todo esforço deve ser empreendido pelas equipes das áreas da educação e da saúde, para que haja uma aproximação entre elas e uma comunicação clara. Expor os progressos e dificuldades da criança em relação ao seu desenvolvimento, assim como características comportamentais e preferências pode auxiliar na adaptação escolar. Além disso, a mobilização desses setores poderá se refletir no aumento da confiança da família e reforçar a escolha pela escola regular. Certamente, o empenho de cada profissional, nesse processo, resultará em benefícios não só para as famílias, mas para todos os envolvidos.

\section{CONClusões}

Este estudo permitiu conhecer as experiências de famílias de crianças com síndrome de Down no processo de inclusão, particularmente aquelas relacionadas à primeira inclusão da criança na rede regular de ensino, a fim de levantar suas necessidades e, assim, contribuir para o sucesso da transição dessas crianças, da instituição especializada para a rede regular de ensino.

No processo de transição da APAE para a escola regular, nenhum participante se sentiu seguro para dizer que era o momento certo para iniciar o processo de inclusão, mesmo tendo tido a oportunidade de receber apoio, formalizado nas discussões grupais a esse respeito, coordenadas pela psicóloga, durante a permanência do filho na instituição especializada, anteriormente a esse processo. As mães demonstraram medo, insegurança e preocupação em vários aspectos, dentre eles, da descontinuidade dos atendimentos terapêuticos que seus filhos recebiam na instituição especializada. Esses sentimentos motivaram as mães a buscar serviços para continuar o tratamento de seus filhos com profissionais particulares ou em serviços públicos, quando ainda estavam vinculados à $\mathrm{APAE}$ ou imediatamente após a saída da instituição. Esses resultados confirmam a necessidade de um trabalho contínuo com as mães, pais ou outros familiares no processo de inclusão da criança, e não somente durante o período em que estas estão frequentando a instituição especializada. Esse acompanhamento tem o objetivo de orientar, apoiar, dar oportunidades para os familiares se expressarem, além de atuar como facilitador das relações entre a instituição especializada, a escola e a família. Além disso, é essencial que profissionais da APAE, em conjunto com profissionais da educação e órgãos públicos, se mobilizem no sentido de oferecer às famílias um leque de possibilidades de atendimentos às crianças, quando estas saírem da instituição especializada, para que o trabalho desenvolvido até então não seja interrompido de forma brusca.

A mobilização entre os setores também se faz necessária para auxiliar a família no processo de escolha pela melhor escola que irá receber a criança. Os profissionais da instituição especializada, por exemplo, utilizando exemplos de outras famílias nesse processo, podem ajudar as mães nessa escolha, além de tranquilizá-las. Em casos onde haja a necessidade de visita prévia para conhecer a 
escola, de modo a dar oportunidade para a família conhecê-la e tempo para refletir e tomar a decisão certa, esses profissionais podem atuar como mediadores entre a família e a escola, já que o vínculo entre eles está consolidado.

O processo de inclusão da criança com SD na rede regular de ensino ainda é um evento novo em nosso contexto, o qual pode gerar tensão e ansiedade nas famílias. A facilidade ou a dificuldade com que essas famílias enfrentarão esse processo tem relação direta com sua trajetória de vida e, dentre outros, com o apoio social e rede social da família, habilidades de comunicação e recursos disponíveis. Cabe aos profissionais envolvidos estarem alertas para a necessidade de constante coleta e atualização de dados nas famílias, durante todo o processo de inclusão, para que possam auxiliá-las, planejando e realizando intervenções criativas e adequadas às suas necessidades.

\section{REFERÊNCIAS}

ABDELHAMEED, H. Desenvolvimento e prestação de serviços educacionais para crianças portadoras de deficiência intelectual no Egito. Revista Brasileira de Educação Especial, Marília, v.16, n.1, p.3-18, 2010.

BRASIL. Constituição (1988). Constituição da República Federativa do Brasil: promulgada em 5 de outubro de 1988. 24. ed. São Paulo: Saraiva, 2000. (Série Legislação Brasileira)

BRASIL. MINISTÉRIO DA SAÚDE. Secretaria Executiva. Núcleo Técnico da Política Nacional de Humanização. Acolhimento com avaliação e classificação de risco: um paradigma ético-estético no fazer em saúde. Brasília: Ministério da Saúde, 2004. Série B. Textos Básicos de Saúde.

BRASIL. MINISTÉRIO PÚBLICO FEDERAL. Procuradoria Federal dos Direitos do Cidadão. Fundação Procurador Pedro Jorge de Melo e Silva. O acesso de alunos com deficiência às escolas e classes comuns da rede regular. Brasília: Procuradoria Federal dos Direitos do Cidadão, 2004.

CUCKLE, P. Getting in and staying there: children with Down syndrome in mainstream schools. Downs Syndrome Research and Practice, Inglaterra, v.6, n.2, p.95-99, 1999.

DE GRAAF, G. Supporting the social inclusion of students with Down syndrome in mainstream education. Down Syndrome News and Update, Reino Unido, v.2, n.2, p.55-62, 2002.

DORZIAT, A. A inclusão nas escolas de $1^{\circ}$ ciclo de ensino básico de Lisboa: algumas considerações. Revista Brasileira de Educação Especial, Marília, v.15, n.2, p.269-288, 2009.

FERRAZ, C. R. A.; ARAÚJO, M. V.; CARREIRO, L. R. R. Inclusão de crianças com síndrome de Down e paralisia cerebral no ensino fundamental I: comparação dos relatos de mães e professores. Revista Brasileira de Educação Especial, Marília, v. 16, n. 3, p. 397-414, 2010.

GONÇALVES, F. D. et al. A promoção da saúde na educação infantil. Interface, Botucatu, v.12, n.24, p.181-192, 2008.

HOLDEN, B.; STEWART, P. The inclusion of students with Down syndrome in New Zealand schools. Down Syndrome News and Update, Reino Unido, v.2, n.1, p.24-28, 2002. 
LEAL, E. N. A criança com síndrome de Down: expectativa da mãe sobre o processo de inclusão escolar. 2006. 107 f. Dissertação (Mestrado) - Faculdade de Filosofia, Ciências e Letras de Ribeirão Preto, Universidade de São Paulo, 2006

LUIZ, F. M. R. et al. A inclusão da criança com síndrome de Down na rede regular de ensino: desafios e possibilidades. Revista Brasileira de Educação Especial, Marília, v.14, n.3, p.497-508, 2008.

MAYAN, M.J. Análisis de datos. In: MAYAN, M.J. Una introducción a los métodos cualitativos: módulo de entrenamiento para estudiantes e profesionales. [S.1.]: Qual Institute Press, 2001. p.22-26.

OLIVEIRA, I. A. Saberes, imaginários e representações na educação especial. Petrópolis: Vozes, 2004.

SALAMANCA. Conferência mundial sobre necessidades educativas especiais: acesso e qualidade. Salamanca: UNESCO, 1994

SILVA, L. M. O estranho causado pela deficiência: preconceito e experiência. Revista Brasileira de Educação, Belo Horizonte, v.11, n.33, p.424-434, 2006.

TAKASE, E. M.; CHUN, R. Y. S. Comunicação e inclusão de crianças com alterações de linguagem de origem neurológica na perspectiva de pais e educadores. Revista Brasileira de Educação Especial, Marília, v.16, n.2, p.251-264, 2010.

UNESCO. Declaração mundial sobre educação para todos: Satisfação das necessidades básicas de aprendizagem, Jomtien, 1990.

Recebido em: 03/06/2011

Reformulado: 17/10/2011

Aprovado: $17 / 10 / 2011$ 
LUIZ, F. M. R.; NASCIMENTO, L. C. 